\title{
Body size dissatisfaction among young Chinese children in Hong Kong: a cross-sectional study
}

\author{
Gemma Knowles ${ }^{1}$, Fiona Chun Man Ling ${ }^{2}$, G Neil Thomas ${ }^{1,3}$, Peymane Adab ${ }^{1}$ and \\ Alison M McManus ${ }^{4,5, *}$ \\ 'Department of Public Health, Epidemiology and Biostatistics, University of Birmingham, Birmingham, UK: \\ ${ }^{2}$ Department of Physical Education and Sport Sciences, University of Limerick, Limerick, Republic of Ireland: ${ }^{3}$ Institute \\ of Public Health, Social and Preventive Medicine, Mannheim Medical Faculty, Heidelberg University, Mannheim, \\ Germany: ${ }^{4}$ School of Health and Exercise Sciences, University of British Columbia, 3333 University Way - \\ ARTS127, Okanagan, Kelowna, British Columbia, Canada, V1V 1V7: Institute of Human Performance, University \\ of Hong Kong, Hong Kong SAR, People's Republic of China
}

Submitted 30 July 2013: Final revision received 24 March 2014: Accepted 3 April 2014: First published online 20 May 2014

\begin{abstract}
Objective: To determine the potential predictors of body size dissatisfaction in Chinese children.

Design: The Child's Body Image Scale was used to assess body size perception and dissatisfaction. BMI was calculated from objectively measured height and weight. Predictors of body size dissatisfaction were examined by logistic regression analysis.

Setting: Hong Kong, China.

Subjects: Six hundred and twenty children ( $53 \%$ boys, aged $6 \cdot 1-12 \cdot 9$ years) from a state-run primary school.

Results: Female sex (adjusted OR $(\mathrm{AOR})=1.91 ; 95 \%$ CI 1.32, 2.76), age $(\mathrm{AOR}=2 \cdot 62 ; 95 \% \mathrm{CI} 1 \cdot 65,4 \cdot 16$ for $8-10$ years; $\mathrm{AOR}=2 \cdot 16 ; 95 \%$ CI $1 \cdot 38,3 \cdot 38$ for $>10$ years), overweight $(\mathrm{AOR}=6.23 ; 95 \% \mathrm{CI} 3.66,10 \cdot 60)$ and obesity $(\mathrm{AOR}=19 \cdot 04 ; 95 \% \mathrm{CI} 5 \cdot 64,64 \cdot 32)$ were positively associated with desire to be thinner. Size misperception was a strong predictor of body size dissatisfaction, irrespective of actual weight status (AOR $=1.90 ; 95 \%$ CI $1.02,3.54$ for overestimation; $\mathrm{AOR}=0.43 ; 95 \% \mathrm{CI} 0 \cdot 27,0.67$ for underestimation).

Conclusions: Body size dissatisfaction is prevalent among Chinese children as young as 6 years. Female sex, age, overweight, obesity and overestimation of size were associated with increased desire to be thinner. These findings emphasise the importance of preventing body image issues from an early age.
\end{abstract}

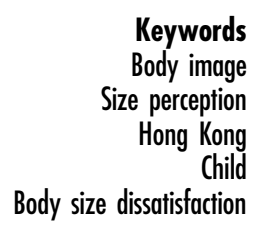

Keywords

Size perception Child

Body size dissatisfaction
A high prevalence of body size dissatisfaction (BSD) has been reported among adolescents in the USA and Europe $^{(1,2)}$ and, more recently, in Asian countries including China ${ }^{(3-5)}$. In cross-sectional and prospective studies of adolescents and young adults, BDS is predictive of low self-esteem ${ }^{(6,7)}$, depressive symptoms ${ }^{(3,7-10)}$, sleep disturbance, stress and low confidence in social situations, often irrespective of actual weight status ${ }^{(4,11)}$.

Until recently BSD was thought to emerge during adolescence $^{(12,13)}$, but new research suggests that children develop concerns about their size at a younger age ${ }^{(1,14-16)}$. A positive association between BMI and BSD has been observed in UK South Asian children as young as 5 years of age ${ }^{(14)}$. Children as young as 4 years have expressed negative attitudes towards a 'fat' body shape ${ }^{(15)}$ and BSD is associated with restrained eating by the age of 9 years ${ }^{(17)}$.
In a population-representative study of Hong Kong (HK) adolescents, significant sex differences in body size misperception were reported ${ }^{(3)}$. Girls were more likely to misperceive their body size than boys. Sex differences in BSD have also been reported in 9-10-year-old children in Beijing in the north of China ${ }^{(18)}$. These sex differences may be indicative of a culture in which it is socially acceptable, perhaps even desirable, for boys to be relatively large, while girls feel the pressure to conform to the 'ideal thin' physique. Whether these patterns exist in young HK Chinese children is currently unknown.

As the prevalence of childhood obesity in China and HK converges towards that of Western countries ${ }^{(19,20)}$, it becomes increasingly important to understand the extent of body image concerns and predictors of BSD in this population. Therefore, the aim of the present study was to 
determine the extent and potential predictors of BSD in young HK Chinese children.

\section{Methods}

\section{Participants and study design}

Participants were HK Chinese children, aged $6 \cdot 1$ to 12.9 years (mean age: 9.2 (sD 1.7) years), from a governmentrun primary school in HK. All children in all year groups were eligible to take part. Of a possible 660 children, 620 (95\%) are included in the present study (53\% male). The $5 \%$ of children excluded from the present analysis were either absent on the day of measurement or did not provide body image and/or anthropometric data. All procedures were approved by the Hong Kong University Hospital Authority Cluster West ethics committee and written parental consent and child assent was obtained for all participants.

\section{Anthropometric measures}

Children attended the session barefoot and in light clothing. Height was measured in duplicate to the nearest $0.1 \mathrm{~cm}$ using a portable stadiometer (Invicta 2007246, Leicester, UK). The average of the two readings was used in the analysis. Weight was measured to the nearest $0 \cdot 1 \mathrm{~kg}$ using Tanita bio-impedance scales (Tanita TBF-410, Japan). BMI was calculated $\left(\mathrm{kg} / \mathrm{m}^{2}\right)$, and weight status (underweight, normal weight, overweight, obese) was defined according to the age- and sex-specific criteria of the International Obesity Task Force (IOTF) ${ }^{(21)}$ that are based on data from six countries including HK. These international reference data, as opposed to local reference data, were chosen for the present study primarily because the BMI range covered by the categories of the Child's Body Image Scale (CBIS) is known to represent the BMI distribution of the IOTF reference data ${ }^{(16)}$. Moreover, use of the IOTF definitions facilitates comparison with existing studies.

\section{The Child's Body Image Scale}

The CBIS, a body image assessment tool for young children, consists of seven gender-specific photo images of children ranging from very thin to obese ${ }^{(1)}$. For the present study, the CBIS was translated into Chinese and administered on a class-by-class basis, following anthropometric measurements. All children were informed that there were no right or wrong answers and were assured of the confidentiality of their responses. Chinese-speaking researchers were present to check understanding of the task, provide assistance as needed and ensure that children did not communicate with their peers while completing the questions. Children were asked to indicate their perceived size ('Which child looks most like you?') and their ideal size ("Which child would you most like to look like?'). Accuracy of body size perception was calculated as the discrepancy between actual and perceived body size (actual minus perceived), giving a score ranging from +6 to -6 . A positive score indicates underestimation of one's actual body size; a negative score indicates overestimation of actual body size; and a zero score indicates accurate estimation of actual body size. BSD was calculated as the discrepancy between perceived and ideal body size (perceived minus ideal). Positive scores were interpreted as desire to be thinner, negative scores were interpreted as desire to be larger, and a score of zero was interpreted as satisfaction with current body size.

The main advantage of the CBIS is that each photo corresponds to a known BMI percentile range, originally based on the National Center for Health Statistics' 1979 reference data (ranging from the 3 rd to the 97th percentile) ${ }^{(22)}$, and more recently mapped onto the UK90 and IOTF standards ${ }^{(16)}$. This feature allows one to assess the accuracy of a child's perception of his/her own body size, which is not possible with most other scales (for example, Stunkard's rating scale ${ }^{(23)}$ ). The CBIS is a valid measure of size perception in girls as young as 7 years and boys as young as 8 years, and is a good measure of BSD in both boys and girls aged 7-12 years ${ }^{(1)}$. Test-retest reliability of the CBIS is also supported in this age group ${ }^{(16)}$.

\section{Statistical analysis}

The $\chi^{2}$ test and Student's $t$ test were used to examine age and sex differences in participant characteristics and CBIS scores. Logistic regression analyses were used to calculate adjusted odds ratios (AOR) for desire to be thinner, desire to be larger and satisfaction with current size (dependent variables in three separate models), with age group, gender and actual weight status entered as dependent variables in model 1 . Model 2 was further adjusted for perceived weight status. All analyses were performed in the statistical software package PASW Statistics 18. Statistical significance was considered as $P<0 \cdot 05$.

\section{Results}

\section{Participant characteristics}

Children who were excluded from the analysis (5\%) were significantly younger than those who did provide valid data (mean difference -1.5 years, $P<0.001$ ), but were similar in terms of BMI (based on data for nineteen of the forty children excluded from the analyses). Girls and boys were similar in terms of age, height and weight (Table 1). A larger proportion of boys were overweight or obese (28.5\% of males $v \cdot 17 \cdot 4 \%$ of females) and fewer boys were underweight $(6.7 \%$ of males $v .11 .9 \%$ of females, $P<0.01)$. There were no significant age differences in weight status among females. Among boys, the two older age groups were more overweight/obese than the youngest age group ( $<8$ years: $18.3 \%$ v. $33.3 \%$ and $32.1 \%$ of boys aged $8-10$ years and $>10$ years, respectively; $P<0 \cdot 05$; Table 2). Overall, there was a bias towards underestimation 
Table 1 Participants' characteristics and CBIS scores; young Hong Kong Chinese children aged 6.1-12.9 years

\begin{tabular}{|c|c|c|c|c|c|c|c|}
\hline & \multicolumn{2}{|c|}{ All $(n 620)$} & \multicolumn{2}{|c|}{ Males ( $n$ 327) } & \multicolumn{2}{|c|}{ Females ( $n$ 293) } & \multirow[b]{2}{*}{$P$ for sex differences } \\
\hline & Mean or $n$ & SD or $\%$ & Mean or $n$ & SD or $\%$ & Mean or $n$ & SD or $\%$ & \\
\hline Age (years) & $9 \cdot 2$ & 1.7 & $9 \cdot 2$ & 1.8 & $9 \cdot 3$ & 1.7 & NS \\
\hline \multicolumn{8}{|l|}{ Age categories } \\
\hline$<8$ years & 179 & $28 \cdot 9$ & 98 & $30 \cdot 0$ & 30 & $30 \cdot 0$ & \\
\hline $8-10$ years & 209 & 33.7 & 117 & $35 \cdot 8$ & 36 & $36 \cdot 0$ & \\
\hline$>10$ years & 232 & 37.4 & 112 & $34 \cdot 3$ & 34 & $34 \cdot 0$ & NS \\
\hline Height $(m)$ & 1.3 & 0.1 & 1.3 & 0.1 & 1.3 & 0.1 & NS \\
\hline Weight (kg) & $32 \cdot 2$ & $10 \cdot 2$ & $32 \cdot 7$ & $10 \cdot 7$ & 31.7 & 9.6 & NS \\
\hline $\operatorname{BMI}\left(\mathrm{kg} / \mathrm{m}^{2}\right)$ & $17 \cdot 7$ & 3.3 & $18 \cdot 1$ & 3.5 & $17 \cdot 3$ & 3.0 & $<0.01$ \\
\hline \multicolumn{8}{|l|}{ IOTF categories } \\
\hline Underweight & 57 & $9 \cdot 2$ & 22 & $6 \cdot 7$ & 35 & 11.9 & \\
\hline Normal weight & 419 & $67 \cdot 6$ & 212 & $64 \cdot 8$ & 207 & $70 \cdot 6$ & \\
\hline Overweight & 108 & $17 \cdot 4$ & 67 & 20.5 & 41 & $14 \cdot 0$ & \\
\hline Obese & 36 & $5 \cdot 8$ & 26 & 8.0 & 10 & 3.4 & $<0.01$ \\
\hline \multicolumn{8}{|c|}{ Actual CBIS category } \\
\hline 1 & 50 & $8 \cdot 1$ & 37 & $11 \cdot 3$ & 13 & 4.4 & \\
\hline 2 & 111 & $17 \cdot 9$ & 51 & $15 \cdot 6$ & 60 & $20 \cdot 4$ & \\
\hline 3 & 137 & $22 \cdot 1$ & 60 & $18 \cdot 3$ & 77 & $26 \cdot 3$ & \\
\hline 4 & 109 & $17 \cdot 6$ & 71 & 21.7 & 38 & 13.0 & \\
\hline 5 & 139 & 22.4 & 89 & $27 \cdot 2$ & 50 & $17 \cdot 1$ & \\
\hline 6 & 63 & $10 \cdot 2$ & 14 & 4.3 & 49 & $16 \cdot 7$ & \\
\hline 7 & 11 & 1.8 & 5 & 1.5 & 6 & $2 \cdot 0$ & $<0.001$ \\
\hline \multicolumn{8}{|c|}{ Perceived CBIS category } \\
\hline 1 & 97 & $15 \cdot 6$ & 58 & $17 \cdot 7$ & 39 & $13 \cdot 3$ & \\
\hline 2 & 147 & 23.7 & 71 & 21.7 & 76 & $25 \cdot 9$ & \\
\hline 3 & 184 & $29 \cdot 7$ & 111 & 33.9 & 73 & $24 \cdot 9$ & \\
\hline 4 & 114 & 18.4 & 54 & $16 \cdot 5$ & 60 & 20.5 & \\
\hline 5 & 56 & $9 \cdot 0$ & 25 & $7 \cdot 6$ & 31 & 20.5 & \\
\hline 6 & 16 & 2.6 & 6 & 1.8 & 10 & 3.4 & \\
\hline 7 & 6 & 1.0 & 2 & 0.6 & 4 & 1.4 & 0.05 \\
\hline \multicolumn{8}{|c|}{ Ideal CBIS category } \\
\hline 1 & 126 & $20 \cdot 3$ & 73 & $22 \cdot 3$ & 53 & $18 \cdot 1$ & \\
\hline 2 & 175 & $28 \cdot 2$ & 98 & $30 \cdot 0$ & 77 & $26 \cdot 3$ & \\
\hline 3 & 230 & $37 \cdot 1$ & 111 & 33.9 & 119 & $40 \cdot 6$ & \\
\hline 4 & 77 & $12 \cdot 4$ & 36 & 11.0 & 41 & $14 \cdot 0$ & \\
\hline 5 & 8 & $1 \cdot 3$ & 6 & 1.8 & 2 & 1.0 & \\
\hline 6 & 0 & 0.0 & 0 & 0.0 & 0 & 0.0 & \\
\hline 7 & 4 & 0.6 & 3 & 0.9 & 1 & 0.3 & NS \\
\hline
\end{tabular}

CBIS, Child's Body Image Scale; IOTF, International Obesity Task Force.

Values are presented as mean and standard deviation for continuous variables or as number and percentage for categorical variables.

of body size using the CBIS (Table 1). The majority of children (86.2\% of males and $85.0 \%$ of females) selected an ideal size equating to the 25 th percentile or lower (photos 1 to 3 ) and approximately half (52.3\% of males and $44.4 \%$ of females) selected an ideal size equivalent to the 10th percentile or below (photos 1 and 2).

\section{Body size perception}

There were no significant sex differences in body size perception (see Table 3). Children in the lowest two age groups were more likely to overestimate their body size than children aged $>10$ years $(P<0 \cdot 01)$. When stratified by sex, the age differences in body size perception were evident only among boys $(P<0.01)$. Across all age groups, just over a quarter of children correctly estimated their size and over half underestimated (53\%-64\% across age groups). Over half of underweight children thought they were larger than in reality, whereas $67 \%$ of obese children underestimated their size $(P<0 \cdot 001)$. These results were similar for both boys and girls.

\section{Body size dissatisfaction}

There were no significant sex differences in BSD (Table 4). Approximately $50 \%$ of children wanted to be thinner ( $45 \%$ of boys and $51 \%$ of girls) and only a quarter were happy with their size. The youngest age group was considerably more likely to desire a larger body size than the two older age groups $(P<0 \cdot 001)$. This trend was evident in both boys and girls, and across all weight status categories. Approximately $50 \%$ of boys and $55 \%$ of girls in the older two age groups wanted to be thinner, compared with just $30 \%$ in the youngest age group.

There was a strong relationship between higher weight status and desire for a thinner body (Table 4); $10 \%$ of underweight, $40 \%$ of normal-weight, $80 \%$ of overweight and over $90 \%$ of obese children wanted to be thinner $(P<0 \cdot 001)$. Within weight status categories, there were no sex differences in BSD among underweight, overweight or obese children but, among normal-weight children, girls were more likely than boys to desire a thinner body size ( $49.3 \%$ and $32.5 \%$ of normal-weight girls and boys, 
Table 2 Weight status* distribution by age and gender among young Hong Kong Chinese children aged 6.1-12.9 years

\begin{tabular}{|c|c|c|c|c|c|c|c|c|c|}
\hline & \multicolumn{2}{|c|}{ Underweight } & \multicolumn{2}{|c|}{ Normal weight } & \multicolumn{2}{|c|}{ Overweight } & \multicolumn{2}{|c|}{ Obese } & \multirow[b]{2}{*}{$P$} \\
\hline & $n$ & $\%$ & $n$ & $\%$ & $n$ & $\%$ & $n$ & $\%$ & \\
\hline$<8$ years & 9 & $5 \cdot 0$ & 140 & $78 \cdot 2$ & 21 & 11.7 & 9 & $5 \cdot 0$ & \\
\hline $8-10$ years & 21 & 10.0 & 127 & 60.8 & 46 & 22.0 & 15 & $7 \cdot 2$ & \\
\hline $\begin{array}{l}>10 \text { years } \\
\text { Males }\end{array}$ & 27 & 11.6 & 152 & $65 \cdot 5$ & 41 & $17 \cdot 7$ & 12 & $5 \cdot \overline{2}$ & $<0.01$ \\
\hline$<8$ years & 3 & $3 \cdot 1$ & 77 & 78.6 & 12 & $12 \cdot 2$ & 6 & $6 \cdot 1$ & \\
\hline $8-10$ years & 8 & $6 \cdot 8$ & 70 & 59.8 & 29 & $24 \cdot 8$ & 10 & 8.5 & \\
\hline $\begin{array}{l}>10 \text { year } \\
\text { Females }\end{array}$ & 11 & 9.8 & 65 & 58.0 & 26 & $23 \cdot 2$ & 10 & 8.9 & $<0.05$ \\
\hline$<8$ years & 6 & 7.4 & 63 & $77 \cdot 8$ & 9 & $11 \cdot 1$ & 3 & 3.7 & \\
\hline $8-10$ years & 13 & $14 \cdot 1$ & 57 & 62.0 & 17 & 18.5 & 5 & $5 \cdot 4$ & \\
\hline$>10$ years & 16 & $13 \cdot 3$ & 87 & 72.5 & 15 & 12.5 & 2 & 1.7 & NS \\
\hline
\end{tabular}

*Weight status based on the International Obesity Task Force categories for underweight, overweight and obese, defined as BMl crossing through $18.5 \mathrm{~kg} / \mathrm{m}^{2}$, $25.0 \mathrm{~kg} / \mathrm{m}^{2}$ and $30.0 \mathrm{~kg} / \mathrm{m}^{2}$, respectively, at the age of 18 years $^{(21)}$.

Table 3 Body size perception (actual minus perceived size) by sex, age and weight status among young Hong Kong Chinese children aged $6.1-12.9$ years

\begin{tabular}{|c|c|c|c|c|c|c|c|}
\hline & \multicolumn{2}{|c|}{ Overestimation of body size } & \multicolumn{2}{|c|}{ Correct estimation of body size } & \multicolumn{2}{|c|}{ Underestimation of body size } & \multirow[b]{2}{*}{$P$} \\
\hline & $n$ & $\%$ & $n$ & $\%$ & $n$ & $\%$ & \\
\hline \multicolumn{8}{|l|}{ Boys } \\
\hline$<8$ years & 23 & 23.5 & 24 & 24.5 & 51 & 52.0 & \\
\hline $8-10$ years & 22 & $18 \cdot 8$ & 32 & $27 \cdot 4$ & 63 & 53.8 & \\
\hline$>10$ years & 9 & 8.0 & 24 & 21.4 & 79 & 70.5 & $<0.01$ \\
\hline \multicolumn{8}{|l|}{ Girls } \\
\hline$<8$ years & 14 & $17 \cdot 3$ & 22 & $27 \cdot 2$ & 45 & 55.6 & \\
\hline $8-10$ years & 16 & $17 \cdot 4$ & 28 & 30.4 & 48 & $52 \cdot 2$ & \\
\hline$>10$ years & 11 & 9.2 & 39 & 32.5 & 70 & $58 \cdot 3$ & NS \\
\hline \multicolumn{8}{|l|}{ Boys } \\
\hline Underweight & 15 & $68 \cdot 2$ & 6 & $27 \cdot 3$ & 1 & 4.5 & \\
\hline Normal weight & 37 & 17.5 & 56 & $26 \cdot 4$ & 119 & $56 \cdot 1$ & \\
\hline Overweight & 2 & 3.0 & 10 & 14.9 & 55 & $82 \cdot 1$ & \\
\hline Obese & 0 & 0.0 & 8 & $30 \cdot 1$ & 18 & $69 \cdot 2$ & $<0.001$ \\
\hline \multicolumn{8}{|l|}{ Girls } \\
\hline Underweight & 15 & 42.9 & 16 & $45 \cdot 7$ & 4 & 11.4 & \\
\hline Normal weight & 22 & 10.6 & 67 & $32 \cdot 4$ & 118 & 57.0 & \\
\hline Overweight & 1 & 2.4 & 5 & $12 \cdot 2$ & 35 & 85.4 & \\
\hline Obese & 3 & $30 \cdot 0$ & 1 & $10 \cdot 0$ & 6 & $60 \cdot 0$ & $<0.001$ \\
\hline
\end{tabular}

Table 4 Body size dissatisfaction (perceived minus ideal size) by sex, age and weight status among young Hong Kong Chinese children aged $6 \cdot 1-12 \cdot 9$ years

\begin{tabular}{|c|c|c|c|c|c|c|c|}
\hline & \multicolumn{2}{|c|}{ Want to be thinner } & \multicolumn{2}{|c|}{ Satisfied with current weight } & \multicolumn{2}{|c|}{ Want to be larger } & \multirow[b]{2}{*}{$P$} \\
\hline & $n$ & $\%$ & $n$ & $\%$ & $n$ & $\%$ & \\
\hline \multicolumn{8}{|l|}{ Boys } \\
\hline$<8$ years & 30 & $30 \cdot 6$ & 33 & 34.0 & 35 & $35 \cdot 7$ & \\
\hline $8-10$ years & 63 & 53.8 & 25 & 21.0 & 29 & 24.8 & \\
\hline$>10$ years & 54 & 48.0 & 34 & 30.4 & 24 & 21.4 & $<0.01$ \\
\hline \multicolumn{8}{|l|}{ Girls } \\
\hline$<8$ years & 31 & $38 \cdot 3$ & 17 & 21.0 & 33 & $40 \cdot 7$ & \\
\hline $8-10$ years & 55 & $59 \cdot 8$ & 18 & $19 \cdot 6$ & 19 & $20 \cdot 7$ & \\
\hline$>10$ years & 64 & $53 \cdot 3$ & 31 & $25 \cdot 8$ & 25 & $20 \cdot 8$ & $<0.01$ \\
\hline \multicolumn{8}{|l|}{ Boys } \\
\hline Underweight & 2 & $9 \cdot 1$ & 6 & $27 \cdot 3$ & 14 & 63.6 & \\
\hline Normal weight & 69 & 32.5 & 73 & 34.4 & 70 & 33.0 & \\
\hline Overweight & 53 & $79 \cdot 1$ & 11 & $16 \cdot 4$ & 3 & 4.5 & \\
\hline Obese & 23 & 88.5 & 2 & 7.7 & 1 & $3 \cdot 8$ & $<0.001$ \\
\hline \multicolumn{8}{|l|}{ Girls } \\
\hline Underweight & 4 & 11.4 & 10 & 28.6 & 21 & 60.0 & \\
\hline Normal weight & 102 & $49 \cdot 3$ & 52 & $25 \cdot 1$ & 53 & $25 \cdot 6$ & \\
\hline Overweight & 34 & 82.9 & 4 & 9.8 & 3 & 7.3 & \\
\hline Obese & 10 & 100.0 & 0 & 0.0 & 0 & 0.0 & $<0.001$ \\
\hline
\end{tabular}


Table 5 Adjusted odds ratios for desire to be thinner, desire to be larger and satisfaction with current body size among young Hong Kong Chinese children aged $6 \cdot 1-12.9$ years

\begin{tabular}{|c|c|c|c|c|c|c|c|c|c|}
\hline \multirow[b]{2}{*}{ Predictor } & \multicolumn{3}{|c|}{ Desire to be thinner } & \multicolumn{3}{|c|}{ Happy with current size } & \multicolumn{3}{|c|}{ Desire to be larger } \\
\hline & AOR & $95 \% \mathrm{Cl}$ & $P$ & AOR & $95 \% \mathrm{Cl}$ & $P$ & AOR & $95 \% \mathrm{Cl}$ & $P$ \\
\hline \multicolumn{10}{|l|}{ Model 1} \\
\hline \multicolumn{10}{|l|}{ Age } \\
\hline$<8$ years & 1.00 & Ref. & - & 1.00 & Ref. & - & 1.00 & Ref. & - \\
\hline $8-10$ years & $2 \cdot 62$ & $1 \cdot 65,4 \cdot 16$ & $<0.001$ & 0.74 & $0.46,1.20$ & 0.22 & 0.48 & $0.29,0.77$ & $<0.001$ \\
\hline$>10$ years & $2 \cdot 16$ & $1.38,3.38$ & $<0.001$ & $1 \cdot 10$ & $0.71,1.73$ & 0.66 & 0.38 & $0.24,0.61$ & $<0.001$ \\
\hline \multicolumn{10}{|l|}{ Sex } \\
\hline Male & 1.00 & Ref. & - & 1.00 & Ref. & - & 1.00 & Ref. & - \\
\hline Female & 1.91 & $1 \cdot 32,2 \cdot 76$ & $<0.001$ & 0.64 & $0.44,0.93$ & $<0.05$ & 0.77 & $0.52,1.14$ & 0.2 \\
\hline \multicolumn{10}{|l|}{ Weight status } \\
\hline Underweight & 0.13 & $0.05,0.32$ & $<0.001$ & 0.97 & $0.52,1.82$ & 0.93 & 4.88 & $2.69,8.86$ & $<0.001$ \\
\hline Normal weight & 1.00 & Ref. & - & 1.00 & Ref. & - & 1.00 & Ref. & - \\
\hline Overweight & $6 \cdot 23$ & $3.66,10.60$ & $<0.001$ & 0.37 & $0.20,0.67$ & $<0.001$ & 0.15 & $0.06,0.35$ & $<0.001$ \\
\hline Obese & 19.04 & $5 \cdot 64,64.32$ & $<0.001$ & 0.13 & $0.03,0.54$ & $<0.01$ & 0.07 & $0.01,0.49$ & $<0.001$ \\
\hline \multicolumn{10}{|l|}{ Model 2} \\
\hline \multicolumn{10}{|l|}{ Body size perception } \\
\hline Overestimate & 1.90 & $1.02,3.54$ & $<0.05$ & 0.85 & $0.46,1.60$ & 0.62 & 0.61 & $0.32,1.17$ & 0.14 \\
\hline Correct estimate & 1.00 & Ref. & - & 1.00 & Ref. & - & 1.00 & Ref. & - \\
\hline Underestimate & 0.43 & $0.27,0.67$ & $<0.001$ & 1.47 & $0.94,2.32$ & 0.09 & 1.86 & $1 \cdot 15,3.01$ & $<0.001$ \\
\hline
\end{tabular}

AOR, adjusted odds ratio; Ref., referent category.

Model 1: adjusted for age group, sex and weight status. Model 2: adjusted for age group, sex, weight status and body size perception.

respectively; $P<0 \cdot 01)$. Among normal-weight children, those who overestimated their size were more likely to want to be thinner than those who underestimated or correctly estimated their size, and those who underestimated their size were more likely to be satisfied than those who overestimated $(P<0 \cdot 01)$.

\section{Predictors of body size dissatisfaction}

In the logistic regression analysis adjusted for age group and weight status (model 1, Table 5), girls were almost twice as likely as boys to desire a smaller body than their current size $(\mathrm{AOR}=1.91,95 \%$ CI 1.32, 2.76). Compared with the youngest age group, older children were at least twice as likely to desire a smaller body size $(\mathrm{AOR}=2 \cdot 62$; $95 \%$ CI $1.65,4 \cdot 16$ for $8-10$ years; AOR $=2 \cdot 16 ; 95 \%$ CI $1 \cdot 38$, 3.38 for $>10$ years). Compared with normal-weight children, overweight and obese children were over six and nineteen times more likely to want to be thinner, respectively $(\mathrm{AOR}=6 \cdot 23 ; 95 \% \mathrm{CI} 3 \cdot 66,10 \cdot 60$ and $\mathrm{AOR}=19 \cdot 04 ; 95 \% \mathrm{CI}$ 5.64, 64.32).

When body size perception was considered as a predictor of BSD (model 2, Table 5), those who overestimated their size (perceived themselves to be larger than they really are) were almost twice as likely to desire a thinner body $(\mathrm{AOR}=1.90 ; 95 \%$ CI 1.02, 3.54) compared with those who correctly estimated their body size.

\section{Discussion}

\section{Main findings}

Our study is the first to examine the prevalence and potential predictors of BSD in young HK Chinese children.
We observed a high prevalence of BSD among 6-13 year olds: only $25 \%$ of children were satisfied with their size and approximately half desired a thinner body size. Older children ( $>8$ years), and girls, were twice as likely to desire a thinner body compared with younger children, and with boys, respectively. There was a clear dose-response relationship between higher weight status and desire to be thinner. Specifically, overweight and obese children were six and nineteen times more likely to desire a thinner body than their normal-weight peers, after adjusting for age and gender. Another important finding of our study is the potential importance of size misperception as a predictor of BSD. Irrespective of actual body size, children who overestimated their size were almost twice as likely to desire a thinner body compared with children who accurately estimated their size. Nevertheless, girls appeared to have a relatively good awareness of their size from the age of 6 years, whereas boys seemed to become more perceptive of their size at a slightly older age. Taken together, these results suggest that, by the age of 8 years, and possibly younger among girls, HK Chinese children are already aware of the social pressures to conform to, and strive towards, the stereotypical 'thin ideal' physique.

\section{Comparison with other studies}

Our findings support the growing body of evidence which suggests that BSD occurs before adolescence ${ }^{(2,14,24-26)}$. Similar to our findings, previous studies have found that approximately $40 \%$ of pre-adolescent girls ${ }^{(2,17,26,27)}$ and about $30-35 \%$ of boys want to be thinner ${ }^{(1,2)}$. A study of adolescent girls in $\mathrm{HK}^{(5)}$, and another of 18-27-year-old HK Chinese adults ${ }^{(28)}$, found that $75 \%$ expressed a desire to be thinner, a considerably higher prevalence than that 
reported in our study, likely due to the age differences between the study cohorts.

With regard to the predictors of $\mathrm{BSD}$, namely age, female gender and high weight status, our findings are generally in agreement with previous research ${ }^{(14,17,29)}$. For instance, the strong dose-response association between higher weight status and desire to be thinner, observed in our study, has also been reported in similar studies of children in Western countries ${ }^{(14,29)}$. For example, in a cohort of 5-7-year-old South Asian children in the UK, being overweight or obese was associated with a 1.5 unit increase in BSD score, and $52 \%$ and $73 \%$ of overweight and obese children, respectively, wanted to be thinner ${ }^{(14)}$.

In our study, girls were twice as likely to desire a thinner body compared with boys. Previous studies have been inconsistent in reporting sex differences in body image issues in children and adolescents. Some studies report no differences between young boys and girls ${ }^{(14,24)}$, whereas others have reported higher BSD and weight perception among girls ${ }^{(2,17,26-29)}$. It is possible that methodological differences (e.g. silhouette matching tasks ${ }^{(1,23)} v$. videoadjustment techniques; for example, Gardner et $a l^{(30)}$ ) or study population contribute to these discrepancies. Further research is needed to establish whether sex differences in body image distortion and dissatisfaction are due to different cultural expectations on boys and girls or are limitations of body image assessment techniques.

The potential importance of body size misperception as a predictor of BSD has also been reported in crosssectional and prospective studies of adolescents in China ${ }^{(4)}$, the $\mathrm{USA}^{(31)}$ and Norway ${ }^{(32)}$. It seems that, irrespective of weight status, body size misperception is highly predictive of BSD and may also be associated with other adverse outcomes such as depressive symptoms and anxiety ${ }^{(33)}$. With this in mind, it is of concern that, in our study, over $80 \%$ of overweight children, and $70 \%$ of boys in the older age group, underestimated their body size. In a population in which childhood obesity has risen rapidly, especially among young boys ${ }^{(20)}$, it may therefore be important to improve awareness of what constitutes a healthy weight among high-risk children who underestimate their size.

Some authors have argued that a modest amount of BSD may inspire healthy lifestyle changes among overweight and obese people ${ }^{(34)}$ and may therefore be beneficial to those living in a so-called 'obesogenic' environment. However, data from prospective studies suggest that the opposite is true: BSD leads to extreme weight-control behaviours such as unhealthy dieting, eating disorders and binge eating $^{(6,8,35)}$, whereas satisfaction with one's body size is protective against eating disorders, excess weight gain and other unhealthy behaviours such as physical inactivity $^{(11,31,36,37)}$. Prospective studies show that extreme weightloss behaviours are associated with increased BMI gain over time, increased risk of metabolic syndrome, high TAG and accumulation of visceral adipose tissue ${ }^{(31,38)}$. These extreme weight-loss behaviours may occur when one's ideal size is unachievable or unrealistic. It is disconcerting, therefore, that about half of the children in the present study selected an ideal size that was less than or equal to the 10th percentile, and about $85 \%$ selected a picture corresponding to the 25th percentile or lower. Almost identical findings were reported in 7-12-year-old British children ${ }^{(1)}$. Thus, improving body size satisfaction may be an important component of obesity and eating disorder interventions, even in the absence of weight loss. Interventions and educational programmes should focus on the importance of a healthy lifestyle, rather than emphasising unrealistic thin physiques that may inadvertently contribute to the development of body image issues. Further research should also try to explore the extent to which the discrepancies between ideal and perceived size are due to social desirability bias and how much is due to genuine dissatisfaction with one's size as the two concepts are not necessarily synonymous.

\section{Strengths and limitations}

The main strengths of our study are the relatively large cohort of young HK Chinese children, a less frequently studied population in the area of obesity and body image research, and the high response rate (95\%). Our study also benefits from the use of standardised protocols and objective measurement of BMI. Moreover, while many previous studies have been limited to the assessment of BSD only, the use of the valid and reliable CBIS in our study also enabled us to assess body size perception, which appears to be an important determinant of BSD.

Our study has some limitations which should be taken into consideration. First, the CBIS was originally developed for use in white Australian children aged 7-12 years ${ }^{(1)}$. Thus, the application of this tool in non-Caucasian ethnic groups and slightly younger children (in our case, as young as 6 years) who may struggle with comprehension of such tasks may be an issue. However, the children seemed to understand that the focus of the task was on body shape and size, rather than specific facial features, and none seemed deterred by the depiction of non-Chinese children in the CBIS, which is possibly a result of the multicultural ethnic mix in HK and exposure to Western-focused media. Our sample did include seventy-eight children (forty-one boys, thirty-seven girls) who were under the age of 7 years (12.6\%) and we found the younger children considerably more likely to desire a larger body size; it is possible that the 6-year-olds did not understand the task or that this simply reflects the common expectation that children at this younger age to want to be bigger and older.

Additionally, although the CBIS was designed to reflect the BMI distribution of 7-12-year-old children, it does not cover the extreme ends of the scale $(<3$ rd percentile and $>97$ th percentile) and might therefore be inappropriate for very thin or very obese children. This could be a 
limitation in populations such as the Chinese where the BMI distribution is lower than that of many Western countries $^{(21)}$ and where there is a dual burden of overand underweight. In our study, eleven boys and four girls were below the 3 rd percentile and five boys and one girl were above the 97th percentile, but results were unchanged when these children were excluded from the analysis. It is also possible that the tool could be improved by random ordering of the figures to prevent any anchoring effect of having the smallest figure as the first one on the scale.

The CBIS does not take into account desired body composition, body shape or fat distribution; it focuses only on size and assumes that body shape is consistent across children within each BMI category ${ }^{(1,39)}$. It has been suggested that this limitation may lead to inaccurate assessment in boys who might desire a more muscular, lean physique ${ }^{(39)}$. Future research could include a qualitative component to further explore this theory among HK youth. Finally, due to practical issues and time constraints, the CBIS, which was originally intended to be used on a one-to-one basis, was administered on a class-by-class basis in the present study. It is possible that the children were influenced by their peer group while completing the CBIS. However, children were asked not to communicate with their peers while completing the task, the activity was supervised by research assistants and none of the children appeared to be distracted, so it is unlikely that this had any major influence on our findings.

\section{Conclusion}

Our findings add to the growing body of evidence which suggests that BSD and size perception develop at a very early age, particularly among girls. Overweight and obesity, female sex and size misperception are significant risk factors for BSD in children as young as 6 years of age. These findings suggest that young HK children may be susceptible to the social pressures of achieving the stereotypical 'ideal slim' physique. Prospective studies are required to confirm these results. As BSD is a risk factor for future weight gain and eating disorders, early education and prevention of body image concerns should be considered an important component of obesity and eating disorder interventions.

\section{Acknowledgements}

Financial support: This work was supported by the University of Hong Kong Research Council Strategic Research Theme Public Health and Small Project Funding; and a Postgraduate Overseas Research Grant from the University of Birmingham. The funders had no role in the design, analysis or writing of this article. Conflict of interest: None. Authorship: G.K., P.A., G.N.T. and A.M.M. conceived and designed the study; F.C.M.L. and A.M.M. recruited the study participants; G.K., F.C.M.L. and A.M.M. collected the data; G.K. and A.M.M. cleaned and analysed the data; G.K., F.C.M.L., G.N.T., P.A. and A.M.M. interpreted the results; G.K. wrote the first draft of the manuscript; G.K., F.C.M.L., G.N.T., P.A. and A.M.M. critically reviewed and revised the initial manuscript and approved the final manuscript as submitted. Ethics of buman subject participation: All procedures were approved by the Hong Kong University Hospital Authority Cluster West ethics committee and written parental consent and child assent was obtained for all participants.

\section{References}

1. Truby H \& Paxton SJ (2002) Development of the Children's Body Image Scale. Br J Clin Psychol 41, 185-203.

2. Collins ME (1991) Body figure perceptions and preferences among preadolescent children. Int J Eat Disord 10, 199-208.

3. Lo WS, Ho SY, Mak KK et al. (2011) Weight misperception and psychosocial health in normal weight Chinese adolescents. Int J Pediatr Obes 6, e381-e389.

4. Xie B, Chou CP, Spruijt-Metz D et al. (2011) Longitudinal analysis of weight perception and psychological factors in Chinese adolescents. Am J Health Behav 35, 92-104.

5. Lee S \& Lee AM (2000) Disordered eating in three communities of China: a comparative study of female high school students in Hong Kong, Shenzhen, and rural Hunan. Int J Eat Disord 27, 317-327.

6. Killen JD, Taylor CB, Hayward C et al. (1996) Weight concerns influence the development of eating disorders: a 4-year prospective study. J Consult Clin Psychol 64, 936-940.

7. Paxton SJ, Neumark-Sztainer D, Hannan PJ et al. (2006) Body dissatisfaction prospectively predicts depressive mood and low self-esteem in adolescent girls and boys. J Clin Child Adolesc Psychol 35, 539-549.

8. Ohring R, Graber JA \& Brooks-Gunn J (2002) Girls' recurrent and concurrent body dissatisfaction: correlates and consequences over 8 years. Int J Eat Disord 31, 404-415.

9. Stice E \& Bearman SK (2001) Body-image and eating disturbances prospectively predict increases in depressive symptoms in adolescent girls: a growth curve analysis. Dev Psychol 37, 597-607.

10. McCreary DR \& Sasse DK (2000) An exploration of the drive for muscularity in adolescent boys and girls. $\mathrm{J} \mathrm{Am}$ Coll Health 48, 297-304.

11. Huang L, Tao FB, Wan YH et al. (2011) Self-reported weight status rather than BMI may be closely related to psychopathological symptoms among Mainland Chinese adolescents. J Trop Pediatr 57, 307-311.

12. Field AE, Cheung L, Wolf AM et al. (1999) Exposure to the mass media and weight concerns among girls. Pediatrics 103, E36.

13. Hoare P \& Cosgrove L (1998) Eating habits, body-esteem and self-esteem in Scottish children and adolescents. J Psychosom Res 45, 425-431.

14. Pallan MJ, Hiam LC, Duda JL et al. (2011) Body image, body dissatisfaction and weight status in South Asian children: a cross-sectional study. BMC Public Health 11, 21.

15. Musher-Eizenman DR, Holub SC, Edwards-Leeper L et al. (2003) The narrow range of acceptable body types of preschoolers and their mothers. J Appl Dev Psychol 24, $259-272$.

16. Truby H \& Paxton SJ (2008) The Children's Body Image Scale: reliability and use with international standards for body mass index. Br J Clin Psychol 47, 119-124. 
17. Hill AJ, Draper E \& Stack J (1994) A weight on children's minds: body shape dissatisfactions at 9-years old. Int J Obes Relat Metab Disord 18, 383-389.

18. Li YP, Ma GS, Schouten EG et al. (2007) Report on childhood obesity in China (5) body weight, body dissatisfaction, and depression symptoms of Chinese children aged 9-10 years. Biomed Environ Sci 20, 11-18.

19. Ji CY (2008) The prevalence of childhood overweight/ obesity and the epidemic changes in 1985-2000 for Chinese school-age children and adolescents. Obes Rev 9, 78-81.

20. So HK, Nelson EA, Li AM et al. (2008) Secular changes in height, weight and body mass index in Hong Kong children. BMC Public Health 8, 320.

21. Cole TJ, Bellizzi MC, Flegal KM et al. (2000) Establishing a standard definition for child overweight and obesity worldwide: international survey. BMJ 320, 1240-1243.

22. Hamill PV, Drizd TA, Johnson CL et al. (1979) Physical growth: National Center for Health Statistics percentiles. Am J Clin Nutr 32, 607-629.

23. Stunkard AJ, Sorenson T \& Schulsinger F (1983) Use of the Danish adoption registers for the study of obesity and thinness. In The Genetics of Neurological and Psychiatric Disorders, pp. 115-120 [S Kety, LP Rowland, RL Sidman et al., editors]. New York: Raven.

24. Tiggemann M \& Pennington B (1990) The development of gender differences in body-size dissatisfaction. Aust Psychol 25, 306-313.

25. Dohnt HK \& Tiggemann M (2004) Development of perceived body size and dieting awareness in young girls. Percept Mot Skills 99, 790-792.

26. Schur EA, Sanders M \& Steiner H (2000) Body dissatisfaction and dieting in young children. Int J Eat Disord 27, 74-82.

27. Rolland K, Farnill D \& Griffiths RA (1997) Body figure perceptions and eating attitudes among Australian schoolchildren aged 8 to 12 years. Int J Eat Disord 21, 273-278.

28. Cheung YT, Lee AM, Ho SY et al. (2011) Who wants a slimmer body? The relationship between body weight status, education level and body shape dissatisfaction among young adults in Hong Kong. BMC Public Health 11, 835.
29. Presnell K, Bearman SK \& Stice E (2004) Risk factors for body dissatisfaction in adolescent boys and girls: a prospective study. Int J Eat Disord 36, 389-401.

30. Gardner RM, Friedman BN, Stark K et al. (1999) Body-size estimations in children six through fourteen: a longitudinal study. Percept Mot Skills 88, 541-555.

31. Sonneville KR, Calzo JP, Horton NJ et al. (2012) Body satisfaction, weight gain and binge eating among overweight adolescent girls. Int J Obes (Lond) 36, 944-949.

32. Cuypers K, Kvaloy K, Bratberg G et al. (2012) Being normal weight but feeling overweight in adolescence may affect weight development into young adulthood - an 11-year follow up: The HUNT study, Norway. J Obes 2012, 601872.

33. Tang J, Yu Y, Du Y et al. (2010) Association between actual weight status, perceived weight and depressive, anxious symptoms in Chinese adolescents: a cross-sectional study. BMC Public Health 10, 594.

34. Heinberg L, Thompson J \& Matzon J (2001) Body image dissatisfaction as a motivator for healthy lifestyle change: is some distress beneficial? In Eating Disorders. Innovative Directions in Research and Practice, pp. 215-232 [R StriegelMoore and L Smolak, editors]. Washington, DC: American Psychological Association.

35. Stice E, Presnell K \& Spangler D (2002) Risk factors for binge eating onset in adolescent girls: a 2-year prospective investigation. Health Psychol 21, 131-138.

36. Neumark-Sztainer D, Paxton SJ, Hannan PJ et al. (2006) Does body satisfaction matter? Five-year longitudinal associations between body satisfaction and health behaviors in adolescent females and males. J Adolesc Health 39, 244-251.

37. Wardle J, Waller J \& Rapoport L (2001) Body dissatisfaction and binge eating in obese women: the role of restraint and depression. Obes Res $9,778-787$.

38. Tanofsky-Kraff M, Shomaker LB, Stern EA et al. (2012) Children's binge eating and development of metabolic syndrome. Int J Obes (Lond) 36, 956-962.

39. Cohane GH \& Pope HG Jr (2001) Body image in boys: a review of the literature. Int J Eat Disord 29, 373-379. 